Agency Budgets, Cost Information, and Auditing Author(s): Jeffrey S. Banks

Source: American Journal of Political Science, Vol. 33, No. 3 (Aug., 1989), pp. 670-699

Published by: Midwest Political Science Association

Stable URL: http://www.jstor.org/stable/2111068

Accessed: 18-03-2016 16:06 UTC

Your use of the JSTOR archive indicates your acceptance of the Terms \& Conditions of Use, available at http://www.jstor.org/page/ info/about/policies/terms.jsp

JSTOR is a not-for-profit service that helps scholars, researchers, and students discover, use, and build upon a wide range of content in a trusted digital archive. We use information technology and tools to increase productivity and facilitate new forms of scholarship. For more information about JSTOR, please contact support@jstor.org. 


\title{
Agency Budgets, Cost Information, and Auditing*
}

\author{
Jeffrey S. Banks, University of Rochester
}

A model of legislature-agency interaction is analyzed where the agency possesses an informational advantage in that only it knows the cost of its services. The legislature has the ability to audit the agency, where auditing is a costly means of verifying the agency's information. Two different procedures are analyzed for determining the agency's budget: in one, the agency makes a budget request, after which the legislature can either accept or reject the request, or audit the agency and impose a budget equal to the true cost of services. In the other procedure, the legislature can follow a request with a counterproposal to the agency, which can then either accept or reject. Since under both procedures auditing is costly, it will be optimal for the legislature to refrain from auditing a request if the perceived benefits do not outweigh this cost. At issue is the ability of the legislature to impose discipline on the agency's request and final budget through an optimal choice of audit and counterproposal strategies, the extent of the information transmitted through the agency's budget request, and the efficiency of the resulting outcomes. A refinement of the sequential equilibrium concept provides the behavioral predictions for the procedures.

\section{Introduction}

A key ingredient in the determination of governmental policies is the interaction between legislatures and executive agencies. We can think of an agency as being responsible for one "dimension" of a larger policy space that describes the legislature's choice set, where the responsibilities of an agency on its dimension include providing information to, and carrying out the wishes of, the legislature. Hence, decisions by the legislature pertaining to an agency's budget have a fundamental impact on the nature and scope of the government's output, since the budget in effect defines those policies that are implementable by the agency.

In his seminal work, Niskanen (1971) develops an economic model of the budgetary process in which the agency, being the sole provider of its particular "services," is able to use this monopoly power to bias decisions in its favor relative to the preferences of the legislature. A fundamental assumption in Niskanen's model is that the relationship between legislature and agency is predicated on an asymmetry of information concerning parameters relevant to the policy choices and outcomes: the agency, due to "expertise" in its policy domain, possesses superior information concerning the costs and benefits of its services relative to the legislature. Thus the del-

*I would like to thank David Weimer, Barry Weingast, and three referees for valuable comments and suggestions. Financial support by the National Science Foundation through grant SES-8700468 is gratefully acknowledged.

American Journal of Political Science, Vol. 33, No. 3, August 1989, Pp. 670-99

(C) 1989 by the University of Texas Press, P.O. Box 7819, Austin, TX 78713 
egation of authority to the agency in terms of budgetary decisions may lead to a more efficient outcome. The difficulties arise when, as is usually assumed, the preferences of the legislature and the agency, and therefore their decision criteria, fail to coincide. Typical motives for the agency include budget maximization, security, and so forth, while the legislature considers distributional effects, costs versus benefits, and so on. Hence, from the legislative point of view, any efficiency gains due to the delegation of authority to a better-informed agency are potentially mitigated by such a divergence of preferences. Furthermore, the legislature cannot simply ask the agency to reveal its information, for the divergence in preferences will typically imply a willingness on the part of the agency to misrepresent the information. Given these difficulties, Niskanen ignores the issue of information transmission and acquisition and assumes rather that the agency is in complete control of budgetary "agenda," in essence reducing the analysis to that of a single actor. ${ }^{1}$

Miller and Moe (1983) depart from this tradition by incorporating both parties as active participants, while maintaining the assumption that only the agency knows its cost of providing services. (See also Miller, 1977; Fiorina and Noll, 1978; and Spencer, 1980.) In the model the agency announces a supply schedule from which the legislature selects the quantity of services to be produced. Miller and Moe (1983) show that if the agency knows the legislature's demand for services it can have a considerable influence in determining the final output, much as in Niskanen's earlier model.

Given the sequence of events in Miller and Moe (1983), the actual cost of services is irrelevant to the legislature's decision, implying that the legislature need not use resources in determining this cost. Yet this seems to neglect one of the legislature's primary responsibilities in its relationship with an agency, namely, that of oversight (e.g., McCubbins and Schwartz, 1984). If an agency is differentially advantaging itself through its asymmetry of information, then it might benefit the legislature to exert some influence and/or to spend some resources in determining the agency's true cost of services, thereby eliminating the source of the agency's advantage. The legislature has at its disposal the ability to monitor the agency's actions, subpoena the agency's accountants, hold public or private hearings, and so forth, all for the purpose of acquiring information the agency may be unwilling to reveal. Borrowing a phrase from the accounting and tax literatures, we label this the legislature's ability to audit the agency. Such a strategy is not without its cost to the legislature, however; adopting any of the above measures incurs some amount of resources. Thus, in general we can

\footnotetext{
${ }^{1}$ Other "single actor" models, with one or the other party in control of the agenda, include those in Peltzman (1976), Stigler (1971), and Wildavsky (1978). Weingast and Moran (1983) provide an excellent summary of the arguments for either party having control of the agenda.
} 
think of auditing as summarizing the legislature's ability to verify the agency's information, where this verification imposes some positive cost on the legislature.

Bendor, Taylor, and Van Gaalen (1987) develop a model with legislative auditing, where the legislature selects a schedule that describes the agency's budget as a function of its announced service cost as well as the true service cost, if the latter is uncovered through the legislature's investigative capabilities. The true service cost may be one of two values, and the agency, upon observing the budget schedule, decides which of the two values to report. In choosing its budget schedule, the legislature attempts to give the agency the incentive to report truthfully, where this is in part accomplished by setting the "penalty budget," assessed if the agency is discovered reporting falsely, sufficiently low. A crucial assumption in this analysis is that the legislature has the ability to commit to a budget schedule which might not be ex post optimal, given the agency's announcement. In particular, the optimal penalty budget is such that, upon observing a misrepresentation by the agency, the legislature would prefer to impose some other budget than the penalty budget. ${ }^{2}$ Yet ex ante the legislature prefers to make such a commitment, since it generates a more "revealing" strategy on the part of the agency.

This assumption of commitment is nontrivial; it allows the legislature both to threaten and to carry out actions that would not be in its interest ex post (i.e., actions which are not sequentially rational). Further, by selecting such actions prior to the agency's decision, the legislature is assured of relatively advantageous position vis-à-vis the situation without such commitment. The rationale for such an assumption in Bendor, Taylor, and Van Gaalen (1987) rests with the notion that budgeting is actually a repeated game played by the legislature and agency and that the legislature has an incentive to establish a "reputation" for dealing harshly with a deceptive agency. Thus, "precommitting . . . in a one-period model approximates what would emerge as [sequentially rational behavior] in a multiperiod model" (p. 815). While I concur that a multiperiod model is a better description of the reality of the budgetary process, I disagree that an initial attack on such a model should come about by assuming that the "reduced form" of a multiperiod game is essentially a one-period game with commitment. This in essence assumes a portion of that which is to be established in any sort of model, namely the behavior of the participants. Since the number of periods of any such interaction is endogenous, due to the "electoral connection" of the legislature as well as whatever determines the decision cal-

${ }^{2}$ This "dynamic inconsistency" problem is common in the principal-agent literature and more generally in any model that allows one party to commit itself to future actions (see Kydland and Prescott, 1977). 
culus of agencies, it seems more appropriate to derive the sequentially rational behavior of the legislature and agency in a one-period model as a first step in analyzing the more dynamic setting of a multiperiod model. ${ }^{3}$ This is the goal of the current paper.

This paper analyzes a one-period model of the legislature-agency relationship in which the behavior of these parties is assumed to be sequentially rational; we also assume that the true cost of the agency's services can take on one of a continuum of values. Further, we analyze this situation under two different budgetary procedures, each of which describes the sequence of moves for the parties. In the closed procedure, the sequence is as follows: the agency, with knowledge of the cost of its services, makes a budget request to the legislature, which can either accept the budget request, thus agreeing to a monetary transfer of the requested amount in return for the agency's services, reject the request, in which case some "status quo" outcome prevails, or audit the agency. I label this the closed procedure because of its similarity to the closed amendment procedure in Congress: the respondent (e.g., the legislature, the floor of the House) does not possess the ability to propose its own alternative following that requested by the initiator (the agency, the committee). This analogy is not complete, though, given the presence of the auditing strategy for the legislature; if a budget request is audited, the legislature learns the true cost of the services and subsequently makes its accept/reject decision based on an exchange at a budget equal to the true cost. ${ }^{4}$ The open procedure, on the other hand, assumes that following a requested budget the legislature can accept, reject, audit, or make a counterproposal to the agency, which the agency can then either accept or reject; if the counterproposal is rejected, no exchange takes place.

At issue in each procedure is the degree to which the agency's budgetary agenda control is moderated by the ability of the legislature to verify the true cost of the agency's services. Of particular interest is whether or not the behavior of the legislature will provide incentives for the agency to request lower budgets when its true cost of services is low, as is done in Bendor, Taylor, and Van Gaalen (1987). Contrary to their analysis, however, the legislature in the current model is unable to commit ex ante to an auditing schedule (and a budget schedule under the open procedure) to provide such incentives. The equilibrium concept used to analyze the model requires that the legislature's decision to audit be optimal, given the legislature's beliefs about the true cost of services. If auditing were costless, then it would be

${ }^{3}$ Obviously the one-period model is a special case of a multiperiod model.

${ }^{4}$ In a later section of the paper, I assume that this auditing is "imperfect," so that with some probability the true cost of services is not revealed; in such an instance the legislator makes the accept/reject decision based on the budget originally requested by the agency under the closed procedure. 
sequentially rational for the legislature to audit a budget request irrespective of the amount, implying that the agency has no incentive to make its request a function of its true cost. However, if auditing is costly, as is assumed here, it may be optimal for the legislature to forgo an audit if the perceived benefits of the audit were less than its cost, where this comparison depends on the budget requested under the closed procedure and the payoff from a counterproposal under the open. Furthermore, sequential rationality requires that such a counterproposal by the legislature must be equal to that which maximizes its expected utility, given its beliefs about the cost of services.

The actual bargaining process from which an agency's budget is determined is undoubtedly much more complex than either of the procedures considered here. Yet these procedures seem to capture the notion of one or the other party being in control of the budgetary agenda and, as such, can provide insights into the behavior of the parties as a function of this control. In particular, we shall see how the ability of the legislature to make a counterproposal dramatically affects the incentives for the agency to "reveal" cost information through its budget request.

\section{The Basic Model and the Closed Procedure}

As with most models in this area, I equate the behavior and preferences of the legislature with that of a single representative legislator; similarly I model the agency as a unified actor. The interaction between the legislator, $L$, and the agency, $A$, is described as a bilateral monopoly, where $L$ has an inelastic demand for one unit of $A$ 's services. The legislator places a (monetary) value of $v \in(0, \infty)$ on the unit of services; thus, $v$ is the maximum amount $L$ would be willing to pay. The cost of one unit of services, $c$, is known to the agency, while the legislator initially treats $c$ as a random variable distributed with positive density $f(\cdot)$ on the interval $[0, v] .{ }^{5}$ The sequence of moves under the closed procedure is as follows. The agency makes a budget request $b \in \mathbf{R}$ to the legislator, who then has three options: (1) accept the budget request and hence acquire the services at a "price" of $b$; (2) reject the request, in which case no transaction occurs; or (3) audit the request at a cost of $k>0$, which subsequently reveals the true cost of services, and then decide whether or not to acquire the services at a price equal to the cost $c$.

${ }^{5}$ We ignore costs greater than $v$ in deriving the equilibrium behavior of $L$ and $A$, since $L$ will never agree to a budget $b>v$, and feasibility requires that $b>c$. In describing changes in equilibrium behavior from changes in $v$, we can think of the prior $f(\cdot)$ as being defined on the interval $[0, \bar{c}]$, where $\bar{c}>v$, so that an increase in $v$ will increase the relevant range of service costs. 
We model this situation as a game of incomplete information (Harsanyi, 1967-68), where a fictitious player, "Nature," selects the cost of services according to the probability schedule $f(\cdot)$ and where only the agency observes this selection. Since $A$ can make its requested budget contingent on the observed cost, a budget strategy for $A$ is a function $\beta:[0, v] \rightarrow \mathbf{R}$, where $b=\beta(c)$ is the budget request of $A$ if the cost of services is $c$. Since by assumption $A$ has no other sources of exchange or financing, we restrict the set of available budgets to those that render production of the agency's services feasible, so that for all $c, \beta(c) \geqslant c .{ }^{6}$ A strategy for the legislator $L$ will consist of an initial decision to accept, reject, or audit a request and, conditional on auditing, a decision to accept or reject as a function of the true cost. Define an audit strategy for $\mathrm{L}$ as a pair of functions

$$
\begin{aligned}
& \alpha: \mathbf{R} \rightarrow \Delta_{\mathbf{2}}, \\
& \gamma: \mathbf{R} \rightarrow \Delta_{1},
\end{aligned}
$$

where $\Delta_{i}$ is the $i$-dimensional unit simplex. Let $\alpha(b)=\left(\alpha_{1}(b), \alpha_{2}\right.$ $(b)$ ), where $\alpha_{1}(b)$ is the probability $L$ accepts a request of $b ; \alpha_{2}(b)$ is the probability $L$ audits; and $1-\alpha_{1}(b)-\alpha_{2}(b)$ is the probability $L$ rejects. Similarly let $\gamma(c)$ be the probability that $L$ acquires the services following an audit which reveals the cost to be $c$.

Initially we assume that both parties are risk neutral, so that their payoffs can be specified as follows: if a budget request of $b$ is accepted by $L$, then $L$ receives $v-b$ and $A$ receives $b$; if the request is rejected both receive a payoff of 0 ; if a request is audited and subsequently accepted $L$ receives $v-c-k$ and $A$ receives $c$; finally if a request is audited and rejected $L$ receives $-k$ and $A$ receives 0 . Thus the preferences of the agency are Niskanen-like in that $A$ attempts to maximize the budget of the agency. ${ }^{7}$

For the agency, the expected utility from requesting a budget of $b$, given true cost $c$ and auditing strategy $\alpha, \gamma$ by the legislator is

$$
E U_{A}(b, c ; \alpha, \gamma) \equiv \alpha_{1}(b) \cdot b+\alpha_{2}(b) \cdot \gamma(c) \cdot c .
$$

The expected utility for the legislator associated with some auditing strategy will in general depend on the beliefs $L$ possesses concerning the true cost of services. Let $\mu(\cdot \mid b)$ denote $L$ 's beliefs about the value of $c$ upon observing a request of $b$; then $L$ 's expected utility from adopting the audit strategy $\alpha, \gamma$, conditional on observing a request of $b$, is

${ }^{6} \mathrm{An}$ alternative specification would be to have services be provided for budgets less than cost, but at a lower "quality." This would not change any of the results under the closed procedure; a discussion of the effect under the open procedure is in note 17 below.

${ }^{7}$ Alternatively, $A$ could be interested in maximizing the budget surplus $b-c$; however, such a change would not alter the equilibrium predictions. 


$$
\begin{aligned}
E U_{L}(b, \alpha, \gamma ; \mu) & \equiv \alpha_{1}(b) \cdot(v-b) \\
& +\alpha_{2}(b) \cdot\left[\int \gamma(c)(v-c) \mu(c \mid b) d c-k\right] .
\end{aligned}
$$

This situation is one in which there are gains from the exchange of the agency's services to the legislator. The relevant prices (i.e., budgets) at which an exchange can profitably take place are those in the interval $[c, v]$, where the price determines the gains from the exchange to each party (ignoring auditing costs). The preferences of the parties are diametrically opposed, in that the agency prefers higher prices to lower, while the legislator prefers lower to higher. Both however realize that an exchange at some price in $[c, v]$ is preferred to no exchange at all. Thus if no exchange takes place, an inefficient outcome will occur. The legislator also has the ability to impose a price equal to $c$ by incurring the audit cost $k$. Yet $k>0$ implies that any such auditing leads to an inefficient outcome as well, since a price equal to the true service cost could have been agreed to without an audit. The goal then is to determine when an exchange will take place and at what price and whether or not the legislator will resort to an audit.

\section{Equilibrium Behavior}

As with most rational choice models, we examine this interaction between legislator and agency through an equilibrium analysis; that is, our conclusions about the model are derived from properties of the behavior of the participants when each is acting optimally, given the other's actions. The equilibrium concept we employ to analyze this model is a refinement of the sequential equilibrium concept (Kreps and Wilson, 1982). Briefly, a sequential equilibrium consists of a budget strategy $\beta^{*}$ for the agency that is optimal given the audit strategy $\alpha^{*}, \gamma^{*}$ of the legislator, where $\gamma^{*}$ is optimal given any realized cost $c$, and where $\alpha^{*}$ is optimal according to the beliefs $\mu^{*}$ the legislator possesses concerning the true cost of services. Further, these beliefs satisfy Bayes's Rule, given the budget strategy $\beta^{*}$ and the prior belief $f(\cdot)$. This last condition implies that, if the budget $b^{\prime}$ is requested by the agency only if the cost of services is $c^{\prime}$, then upon observing $b^{\prime}$ the legislator should assign probability 1 to the true cost being equal to $c^{\prime}$. If, on the other hand, a subset of costs would imply a request of $b^{\prime}$, then $L$ should place positive probability only on these types and to the degree dictated by the prior $f(\cdot)$.

The sequential equilibrium concept requires the legislator's decision to accept or reject an exchange following an audit to be "sequentially rational," so that in any equilibrium $\gamma$ must satisfy $\gamma(c)=1$, for all $c \leqslant v$. Thus the legislator cannot "threaten" to forgo an exchange, as is allowed under the Nash equilibrium concept. Hence, given the risk neutrality of the leg- 
islator, we can without loss of generality redefine the expected payoffs of the parties as:

$$
\begin{aligned}
& E U_{A}(b, c ; \alpha)=\alpha_{1}(b) \cdot b+\alpha_{2}(b) \cdot c \\
& E U_{L}(b, \alpha ; \mu)=\alpha_{1}(b) \cdot(v-b)+\alpha_{2}(b) \cdot\left[v-c_{\mu}-k\right],
\end{aligned}
$$

where

$$
c_{\mu}=\int c \cdot \mu(c \mid b) d c
$$

is the expected value of $c$, according to the probability $\mu(\cdot)$.

Sequential rationality at the legislator's initial decision requires that if $b>v$ then $\alpha_{1}(b)=0$, while if $b<v \alpha_{1}(b)+\alpha_{2}(b)=1$, so that $L$ will never accept a budget request greater than $v$ and never reject a request less than $v$. Further, $\alpha_{1}(b)=1$ for all $b \leqslant k$, since for any beliefs concerning the true cost of services, the legislator would attain a higher payoff by accepting rather than auditing. Taken together, these restrictions imply that in any equilibrium $\beta(c) \in[\min \{c, k\}, v]$ for all $c$.

Not surprisingly, the equilibrium behavior of the agency and legislator is a function of the audit cost $k$. If $L$ observes a budget request of $b<v$, then acceptance of $b$ generates a payoff to $L$ of $v-b$, while auditing generates $v-c_{\mu}-k$, so that (after rearranging terms) $L$ should accept $b$ if $b<c_{\mu}+k$, and audit if $b>c_{\mu}+k$. If $b=c_{\mu}+k$, the legislator is indifferent between accepting and auditing and hence is able to randomize. Let $k^{*}$ solve

$$
\int_{0}^{v} c \cdot f(c) d c / \int_{0}^{v} f(c) d c=v-k
$$

Thus, if $k=k^{*}$ the legislator is indifferent between accepting and auditing a budget of $v$ requested by all $c \in[0, v]$. For any $k<k^{*}$, define $c^{\prime}$ as that cost which solves

$$
G\left(c^{\prime}, k, v\right) \equiv \int_{c^{\prime}}^{v} c \cdot f(c) d c / \int_{c^{\prime}}^{v} f(c) d c-v+k=0,
$$

so that if all $c \in\left[c^{\prime}, v\right]$ request a budget of $v, L$ is indifferent between accepting and auditing. For all $k<k^{*}, c^{\prime}$ will exist and be such that $c^{\prime}+k<v$.

Our first result characterizes equilibrium strategies of the agency and legislator in which the cost of services is sometimes "revealed" through the agency's requested budget. ${ }^{8}$

${ }^{8}$ One difficulty with the sequential equilibrium concept is that it allows for equilibria that are only supported by "implausible" beliefs at budgets requested with zero probability in equi- 
Proposition 1: If $k<k^{*}$, then the following constitute sequential equilibrium strategies:

$$
\begin{aligned}
& \beta^{*}(c)= \begin{cases}c+k & \text { if } c \in\left[0, c^{\prime}\right] \\
v & \text { if } c \in\left(c^{\prime}, v\right]\end{cases} \\
& \alpha_{1}^{*}(b)= \begin{cases}1 & \text { if } b \leqslant k \\
r(b) & \text { if } b \in\left[k, c^{\prime}+k\right] \\
0 & \text { if } b \in\left(c^{\prime}+k, v\right) \\
s(v) & \text { if } b=v\end{cases} \\
& \alpha_{2}^{*}(b)=1-\alpha_{1}^{*}(b),
\end{aligned}
$$

where

$$
\begin{aligned}
& r(b)=\exp \{(k-b) / k\}, \\
& s(v)=r\left(c^{\prime}+k\right) \cdot k /\left(v-c^{\prime}\right) .
\end{aligned}
$$

Figure 1 visualizes these strategies. For costs $c \leqslant c^{\prime}$ the budget strategy is separating; each cost type requests a different budget. Thus when making the audit decision, the legislator knows precisely what the cost of the service will be. Further, the budget requested is such that $L$ is indifferent between accepting and auditing the budget, allowing $L$ to randomize. Thus even though the true cost is revealed through the budget request strategy, $L$ will proceed to audit the request with some probability. The probability schedule $r(b)$ is then chosen to give each cost type an incentive to request the (equilibrium) budget. Thus $r(b)$ must satisfy $\partial r / \partial b<0$, so that higher budget requests are audited more often. Cost types $c \in\left(c^{\prime}, v\right]$ pool at the budget $b=v$, so that upon observing a request of $v$ the legislator is uncertain as to the true cost of services; $L$ knows only that it is in the interval $\left[c^{\prime}, v\right]$. Given the definition of $c^{\prime}$ in equation (2), the legislator is indifferent between accepting and auditing the budget, implying that again $L$ can randomize. The probability of accepting $b=v$ is then set so that all types $c \in\left(c^{\prime}, v\right]$ prefer to request $b=v$; in particular, given the continuity of $A$ 's utility, $\alpha_{1}(v)$ will be such that $c=c^{\prime}$ will be exactly indifferent between separating at $b=c^{\prime}+k$ and pooling at $b=v$.

\footnotetext{
librium. Further, since such "out-of-equilibrium" behavior nontrivially affects the equilibrium predictions, this lack of restrictions on out-of-equilibrium beliefs generates "unreasonable" equilibria. A number of authors have proposed restrictions on such beliefs (e.g., Cho and Kreps, 1987; Banks and Sobel, 1987; Grossman and Perry, 1986) in an attempt to limit attention to only those equilibria supported by "reasonable" beliefs. One of these refinements, that of "universal divinity" (Banks and Sobel, 1987), is employed here to select a unique equilibrium prediction. A rigorous definition of this concept and the proofs that the equilibria in Propositions 1 and 2 are the unique universally divine equilibria are contained in Appendix A.
} 
Note that at a budget request of $b=v$, the legislator is also indifferent between accepting and rejecting the exchange. Thus one might think that there exist equilibria where $L$ places positive probability on this option as well. As is shown in Appendix A, this will never constitute an equilibrium; the legislator will never reject an exchange if the budget $b=v$ is requested.

The effect of changes in the audit cost $k$ and the value of services $v$ on the equilibrium strategies described in Proposition 1 are fairly obvious: for $c<c^{\prime}$, increasing $k$ leads to an increase in the requested budget, while an increase in $v$ has no effect. For $c>c^{\prime}$, an increase in $k$ has no effect on the requested budget, while an increase in $v$ increases the requested budget. Further, by equation (2) $c^{\prime}$ will be a function of $k$ and $v$ as well. As $k$ increases, $c^{\prime}$ decreases, so that an increase in audit cost implies that more cost

FIGURE 1.A

The Equilibrium Budget Strategy $\left(k \leqslant k^{*}\right)$

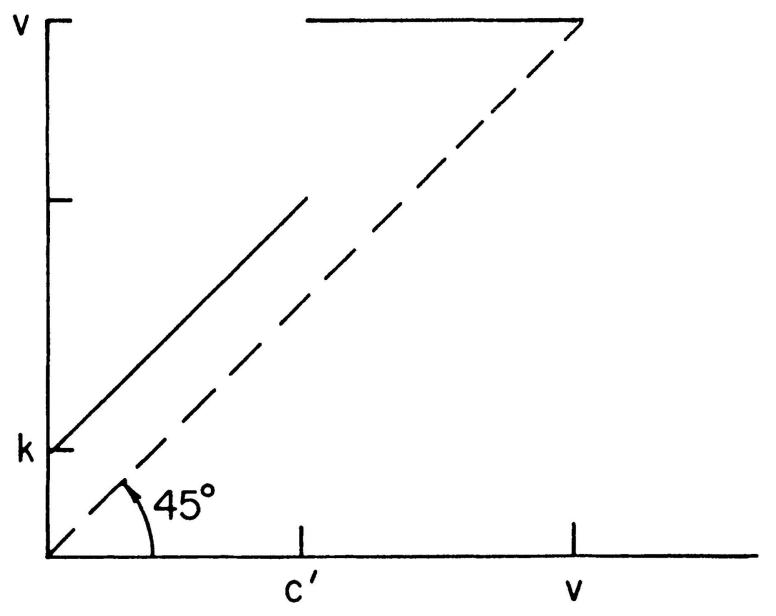

FIGURE 1.B

The Equilibrium Acceptance/Auditing Strategy $\left(\mathrm{k}<\mathrm{k}^{*}\right)$

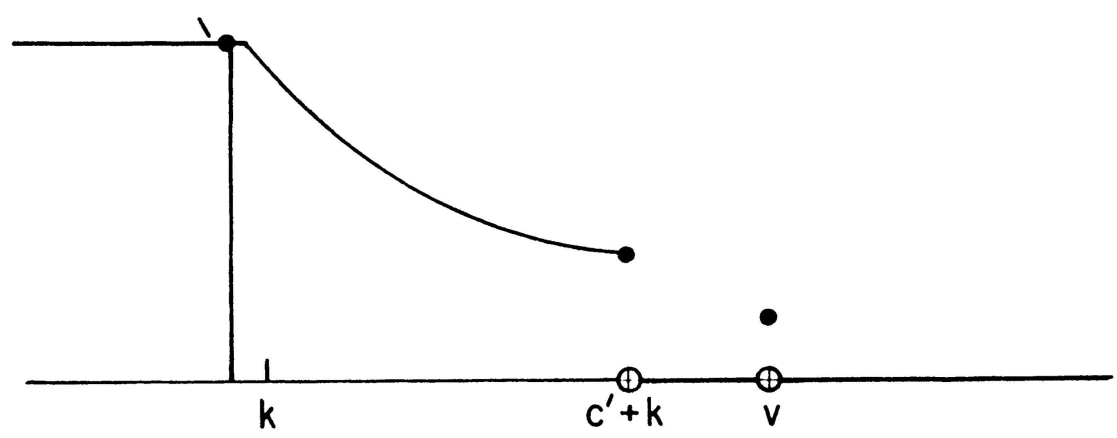


types will pool at the budget request $b=v$ and less will separate at $b=c+k \cdot{ }^{9}$ The one result that cannot be determined without knowledge of the prior probability $f(\cdot)$ is the effect of changes in $v$ on $c^{\prime}$. For some distributions (e.g., uniform) $\partial c^{\prime} / \partial v>0$, so that as $v$ increases, more cost types separate; however, for other distributions, this sign is negative. In terms of the legislator's equilibrium auditing strategy, it is easily shown that for any requested budget the probability of auditing decreases as $k$ increases, while a change in $v$ has no effect.

An interesting feature of this equilibrium is that for $c<c^{\prime}$ the legislator is at times agreeing to an exchange at a budget that is known to be above the service cost $c$; that is, the agency's strategy is such that the requested budget reveals the true cost and at a budget that is strictly greater than this cost. Hence, although the legislator is paying more than is required, $L$ is prohibited under the closed procedure from making a counterproposal to the agency. In this way we see how the agency uses its agenda control to extract some of the gains from exchange from the legislator while simultaneously revealing its true service cost. The presence of the legislator's auditing strategy mitigates this behavior, however, since cost types $c<c^{\prime}$ request budgets that are strictly less than the "monopoly price" $v$. Hence, the legislator receives a portion of the gains from exchange as well. Later we shall see how these predictions are dramatically altered when the legislator has the ability to make a budgetary counterproposal.

Let $B(c ; k, v) \equiv E U_{A}\left(c, \beta^{*}(c) ; \alpha^{*}\left(\beta^{*}(c)\right)\right)$ denote the expected budget for the agency, given the equilibrium strategies $\beta^{*}, \alpha^{*}$, service $\operatorname{cost} c$, and parameters $k, v$. For all cost types $c<c^{\prime}$, the expected budget is

$$
B(c ; k, v)=c+k \cdot \exp \{-c / k\} .
$$

Thus, $\partial B / \partial c=1-\exp \{-c / k\}>0$, so that the expected budget is increasing in $c$. For cost types $c>c^{\prime}$,

$$
B(c ; k, v)=c+\exp \left\{-c^{\prime} / k\right\} \cdot k(v-c) /\left(v-c^{\prime}\right),
$$

so that $\partial B / \partial c=1-\exp \left\{-c^{\prime} / k\right\} \cdot k /\left(v-c^{\prime}\right)>0$. Figure 2 graphs the equilibrium expected budget of the agency as a function of the cost of services. From Figure 2 it is clear that the expected budget surplus, $B$ $(c ; k, v)-c$ is a decreasing function of the service cost $c$. Hence, the largest budget surplus occurs when the cost of services is at its lowest.

The effect of changes in the parameters $k$, $v$, on the agency's expected budget are as follows: increasing the audit cost increases the agency's expected budget. For $c \in\left[0, c^{\prime}\right)$ the expected budget is invariant to changes

\footnotetext{
${ }^{9}$ The result that $\partial c^{\prime} / \partial k<0$, as well as the effects of changes in $k$ and $v$ on $B, V$, and $P$ are contained in Appendix A.
} 
in $v$. For $c \in\left[c^{\prime}, v\right]$ things are a little trickier. Suppose that $\partial c^{\prime} / \partial v>0$; then (as shown in Appendix A) there exists a cost $c^{+} \in\left(c^{\prime}, v\right)$ such that for $c \in\left[c^{\prime}, c^{+}\right)$the expected budget is decreasing in $v$, while for $\mathrm{c}$ $c \in\left(c^{+}, v\right]$ the expected budget is increasing in $v$.

Next we turn to the expected utility for the legislator derived from the equilibrium strategies in Proposition 1:

$$
V(k, v) \equiv \int_{0}^{v} E U_{L}\left(\beta^{*}(c), \alpha^{*}\left(\beta^{*}(c)\right)\right) f(c) d c .
$$

For cost types $c \in\left[c^{\prime}, v\right]$ the utility for the legislator is zero, since these types are requesting a budget of $b=v$, and $L$ is indifferent between accepting and rejecting. For cost types $c \in\left[0, c^{\prime}\right]$ the utility for the legislator is equal to $v-c-k$, since the requested budget is chosen to leave $L$ indifferent. Thus the ex ante expected utility to $L$ is equal to

$$
V(k, v)=\int_{0}^{c^{\prime}}(v-c-k) f(c) d c .
$$

FIGURE 2

The Equilibrium Expected Budget $\left(k<k^{*}\right)$

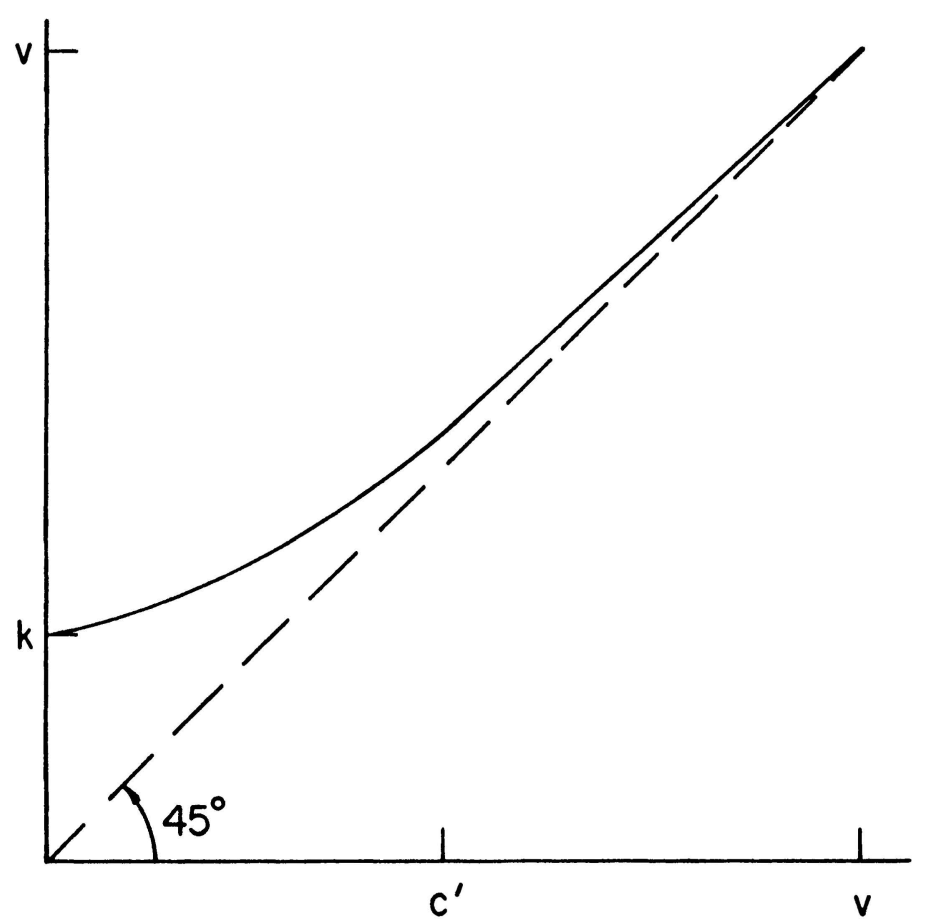


Not surprisingly $V$ decreases with an increase in the auditing cost $k$. When $k$ increases, more cost types pool at $b=v$, thus depriving $L$ of any positive payoff; further the budgets requested by cost types $c<c^{\prime}$ are larger. If $\partial c^{\prime} / \partial v>0$ then $V$ will be an increasing function of the value of services $v$, which seems to make intuitive sense. On the other hand, if $\partial c^{\prime} / \partial v<0$ the sign of $\partial V / \partial v$ will depend on the following trade-off: increasing $v$ implies that less types separate, but for those that do the payoff to $L$ is larger. If there is a "spike" in the density $f(\cdot)$ at $c$ ', then the legislator may not prefer a marginal increase in the value of services, since this would imply an unacceptably large fraction of cost types switching to the pooled budget request at $b=v$.

Finally, let

$$
P(k, v) \equiv \int_{0}^{v} \alpha_{2}^{*}\left(\beta^{*}(c)\right) f(c) d c
$$

be the ex ante probability that an audit occurs, and

$$
N(k, v) \equiv \int_{0}^{v}\left[1-\alpha_{1}^{*}\left(\beta^{*}(c)\right)-\alpha_{2}^{*}\left(\beta^{*}(c)\right] f(c) d c\right.
$$

be the ex ante probability of no exchange. We can think of these as measures of the inefficiency of the agency's and legislature's equilibrium behavior. From Proposition 1,

$$
\begin{aligned}
& P(k, v)=\int_{0}^{c^{\prime}}(1-\exp \{-c / k\}) f(c) d c+\left[1-\exp \left\{-c^{\prime} / k\right\} k /\right. \\
& \left.\left(v-c^{\prime}\right)\right] \cdot \int_{c^{\prime}}^{v} f(c) d c
\end{aligned}
$$

and

$$
N(k, v)=0 .
$$

There are two opposing effects operating on $P$ when the audit cost $k$ increases: for cost types $c<c^{\prime}$ the probability of an audit is decreasing, but since $\partial c^{\prime} / \partial k<0$ some cost types are switching from separating at $c+k$ to pooling at $b=v$, and since $r\left(c^{\prime}+k\right)<s(v)$ these types are faced with a higher probability of audit. Thus the effect will in general depend on the prior $f(\cdot)$; a similar conclusion holds for $\partial P / \partial v$. Suppose $f(\cdot)$ satisfies the following inequality:

$$
\int_{c^{\prime}}^{v} f(c) d c \geqslant f\left(c^{\prime}\right) \cdot\left(v-c^{\prime}\right)
$$

For example, if $f\left(c^{\prime}\right)$ is not "too large" or if $f(\cdot)$ is nondecreasing on the interval $\left(v-c^{\prime}, v\right)($ e.g., $f(\cdot)$ is uniform), then the above inequality will hold. In this instance, then, increasing the audit cost decreases the ex ante probability of an audit $P$, while if in addition $\partial c^{\prime} / \partial v>0$ then increasing the value of services increases $P$. 
The equilibrium described in Proposition 1 exists whenever $k<k^{*}$, so that it is possible for a subset of cost types to request $b=v$ and leave the legislator indifferent between accepting and auditing the budget. Clearly, then, this equilibrium will not exist when $k>k^{*}$, since for these audit costs even if all of the cost types request $b=v$ the legislator would be willing to accept.

Proposition 2: If $k>k^{*}$, then the following constitute sequential equilibrium strategies:

$$
\begin{array}{ll}
\beta^{*}(c)=v, & \text { for all } c \in[0, v] \\
\alpha_{1}^{*}(b)=1, & \text { for all } b \leqslant v .
\end{array}
$$

Thus, if the cost of auditing the agency's budget request is sufficiently high, the agency can use its agenda control to extract the total available surplus from the exchange. In this instance

$$
\begin{aligned}
& B(c ; k, v)=v, \quad \text { for all } c \in[0, v], \\
& V(k, v)=0, \\
& P(k, v)=0, \quad \text { and } \\
& N(k, v)=0 .
\end{aligned}
$$

The effect of changes in the parameters $k, v$, are obvious.

As an example, suppose that the cost of services is distributed uniformly on the interval $[0, \bar{c}]$, where $\bar{c}>v$. Then the critical values $k^{*}$ and $c^{\prime}$ take on particularly simple forms: $k^{*}=v / 2, c^{\prime}=v-2 k$. Hence, as long as the audit cost is less than half the value of the services, the expected net value of the exchange for the legislator will be positive, as cost types $c \in[0, v-2 k]$ request the amount $c+k$.

As noted above there are two possible sources of inefficiency in the interaction between agency and legislator: (1) no exchange and (2) the legislator audits. Propositions 1 and 2 imply that the first type of inefficiency does not occur under the closed procedure, while the second type occurs only if $k<k^{*}$. Hence, if $k>k^{*}$, the equilibrium outcome is efficient. Of course in this instance, the equilibrium payoffs are highly skewed; the agency receives all of the potential gains from the exchange. Thus if $k<k^{*}$ the outcome is somewhat more "equitable," in that both parties receive positive gains from the exchange, yet the outcome is inefficient; if $k>k^{*}$ the outcome is not equitable, yet is efficient.

\section{Imperfect Auditing}

The basic model outlined above assumes that the auditing technology of the legislator is "perfect" in the sense of always determining the true cost 
of the services. In this section we relax this assumption in the following manner: with probability $\lambda>0$ an audit is "successful," and the true cost is vealed, while with probability $1-\lambda$ the audit is "unsuccessful" and reveals nothing. As before, given a successful audit, the legislator decides whether or not to acquire the agency's services at the true $\operatorname{cost} c$; given an unsuccessful audit, however, $L$ must under the closed procedure make this decision based on the original budget request $b$. The function $\gamma$ is now defined as

$$
\gamma: \mathbf{R} \times\{0,1\} \rightarrow \Delta_{1},
$$

where 1 is associated with a successful audit. Thus $\gamma(b, 0)$ is the probability that $L$ acquires the services at the budget request $b$ conditional on an unsuccessful audit, and $\gamma(c, 1)$ is the probability $L$ acquires the services given a successful audit reveals the true cost to be $c$.

The expected utility for the agency is now

$$
\begin{gathered}
E U_{A}(b, c ; \alpha, \gamma) \equiv \alpha_{1}(b) \cdot b+\alpha_{2}(b) \cdot[\lambda \cdot \gamma(c, 1) \cdot c \\
+(1-\lambda) \cdot \gamma(b, 0) \cdot b],
\end{gathered}
$$

and that of the legislator is

$$
\begin{aligned}
E U_{L}(b, \alpha, \gamma ; \mu) \equiv & \alpha_{1}(b) \cdot(v-b)+\alpha_{2}(b) \cdot\left[\lambda \cdot \int \gamma(c, 1)\right. \\
& \cdot(v-c) \mu(c \mid b) d c+(1-\lambda) \cdot \gamma(b, 0) \\
& \cdot(v-b)-k]
\end{aligned}
$$

Sequential rationality requires that

$$
\gamma(b, 0)= \begin{cases}1 & \text { if } b<v \\ 0 & \text { if } b>v\end{cases}
$$

and a modification of the proof in Appendix A that $\alpha_{1}(v)+\alpha_{2}$ $(v)=1$ can be used to show that in equilibrium $\gamma(v, 0)=1$. Since $\beta(c) \leqslant v$ for all $c$, in equilibrium an audit is always followed by acceptance, at either the true cost $c$ or the requested budget $b$. Thus the expected utility for the parties simplifies to

$$
\begin{aligned}
E U_{A}(b, c ; \alpha)= & \alpha_{1}(b) \cdot b+\alpha_{2}(b) \cdot[\lambda \cdot c+(1-\lambda) \cdot b], \\
E U_{L}(b, \alpha ; \mu)= & \alpha_{1}(b) \cdot(v-b)+\alpha_{2}(b) \cdot\left[v-\left(\lambda \cdot c_{\mu}\right.\right. \\
& +(1-\lambda) \cdot b)-k] .
\end{aligned}
$$

Canceling terms, we can characterize the decision calculus for the legislator as follows: if $b<c_{\mu}+k / \lambda, L$ should accept, while if $b>$ $c_{\mu}+k / \lambda, L$ should audit. Define $\pi=k / \lambda$ and let $\pi^{*}$ solve

$$
\int_{0}^{v} c \cdot f(c) d c / \int_{0}^{v} f(c) d c=v-\pi
$$


Similarly, for any $\pi<\pi^{*}$ define $c^{\prime}$ as the cost which solves

$$
G\left(c^{\prime}, \pi, v\right) \equiv \int_{c^{\prime}}^{v} c \cdot f(c) d c / \int_{c^{\prime}}^{v} f(c) d c-v+\pi=0 .
$$

Clearly the decision criteria for the legislator is a simple transformation of that from the earlier model, where the value $\pi=k / \lambda$ has replaced the value $k$. This then implies the next result.

\section{Proposition 3:}

(1) If $\pi>\pi^{*}$, then there exist sequential equilibrium strategies equivalent to those in Proposition 2.

(2) If $\pi<\pi^{*}$ and $\lambda$ is sufficiently close to 1 , then the following constitute sequential equilibrium strategies:

$$
\begin{aligned}
& \beta^{*}(c)= \begin{cases}c+\pi & \text { if } c \in\left[0, c^{\prime}\right] \\
v & \text { if } c \in\left(c^{\prime}, v\right]\end{cases} \\
& \alpha_{1}^{*}(b)= \begin{cases}1 & \text { if } b \leqslant \pi \\
r(b) & \text { if } b \in\left(\pi, c^{\prime}+\pi\right] \\
0 & \text { if } b \in\left(c^{\prime}+\pi, v\right) \\
s(v) & \text { if } b=v\end{cases} \\
& \alpha_{2}^{*}(b)=1-\alpha_{1}^{*}(b),
\end{aligned}
$$

where

$$
\begin{aligned}
& r(b)=[\exp \{(\pi-b) / \pi\}-(1-\lambda)] / \lambda \\
& s(v)=\left[r\left(c^{\prime}+\pi\right) \cdot \pi-(1-\lambda)\left(v-c^{\prime}\right)\right] / \lambda \cdot\left(v-c^{\prime}\right) .
\end{aligned}
$$

Hence if $\lambda$ is close to 1 , then the strategies are analogous to those in the original model, namely, if $\pi<\pi^{*}$ low cost types separate while high cost types pool at $b=v \cdot{ }^{10}$ Further, the separating requests leave the legislator indifferent between accepting and auditing and hence able to randomize. The randomization schedule is then chosen to give the agency the incentive to request $c+\pi$. Thus there is continuity in the equilibrium strategies as $\lambda$ approaches 1 , implying that the perfect auditing model is a useful approximation to the situation where $\lambda$ is "close to" 1 .

Working through the algebra, we see that the equilibrium expected budget for the agency takes on a similar form to that of the basic model as well:

$$
\begin{aligned}
& B(c ; k, \lambda, v)= \\
& \left\{\begin{array}{l}
c+\exp \{-c / \pi\} \cdot \pi \\
c+\left[\exp \left\{-c^{\prime} / \pi\right\}-(1-\lambda)\right] \pi(v-c) / \lambda\left(v-c^{\prime}\right) \text { if } c \in\left[0, c^{\prime}\right]
\end{array}\right.
\end{aligned}
$$

\footnotetext{
${ }^{10}$ The constraint that $\lambda$ be close to 1 follows from the fact that $s(v)$ must be greater than or equal to zero, since for some values of $c^{\prime}$ and $\lambda$ this term might be negative.
} 
and the equilibrium expected utility for the legislator is

$$
V(k, \lambda, v)=\int_{0}^{c^{\prime}}(v-c-\pi) f(c) d c .
$$

In particular, since $c^{\prime}$ can be written as a function only of $\pi=k / \lambda$ and $v$, there is a simple characterization of the legislator's preferences over auditing technologies (e.g., monitoring, hearings, etc.) generated by the equilibrium behavior described in Proposition 3.2. Suppose that $T$ is a set of auditing technologies, where for each $t \in T$ there is an associated cost $k(t)$ and probability of success $\lambda(t)$. Then the induced preference of $L$ over the set $T$ is defined as follows: a technology $t$ is preferred to $t^{\prime}$ if $k(t) / \lambda(t)<k\left(t^{\prime}\right) /$ $\lambda\left(t^{\prime}\right)$. An optimal auditing technology for $L$ is then one which solves

$$
\underset{t \in T}{\operatorname{minimize}} \frac{k(t)}{\lambda(t)}
$$

Thus it is the ratio of cost to probability of success that determines the relative attractiveness of a particular auditing technology.

Thus far we have been assuming that the agency is risk neutral in terms of preferences over the budget. With imperfect auditing, however, the equilibrium in Proposition 3.2 presents the agency with two sources of uncertainty; namely, whether or not there will be an audit and whether or not such an audit will be successful. Suppose we relax the assumption of the agency's risk neutrality by describing $A$ 's preferences over the budget by a function $g: \mathbf{R} \rightarrow \mathbf{R}$, where $g(0)=0$ and $g^{\prime}>0$. Thus, the agency might be risk averse on low budgets, risk acceptant on high, or whatever.

Proposition 4: If $\lambda$ is sufficiently close to 1 , then the budget strategies in Proposition 3 remain sequential equilibrium budget strategies, regardless of the agency's attitude towards risk.

The logic of this Proposition is as follows: in Proposition 3.2 the determinants of the agency's equilibrium budget strategy are a function only of the legislator's payoffs. Namely, the requested budget for $c<c^{\prime}$ is such that $L$ is indifferent between accepting and auditing, while the critical value $c^{\prime}$ is such that $L$ is indifferent between accepting and auditing a request of $b=v$ from cost types $c \in\left[c^{\prime}, v\right]$. As long as the relevant value for $s(v)$ is nonnegative (which will hold for $\lambda$ close to 1 ), there will exist an auditing strategy that induces the budget strategy in Proposition 3.2.11

${ }^{11}$ The difficulty in analyzing such a model comes from the fact that the auditing schedule which provides the incentive for cost types $c<c^{\prime}$ to separate does not in general have a closedform solution. Define $\psi(b) \equiv g^{\prime}(b) /[g(b)-g(b-\pi)]$; then the appropriate acceptance/ auditing schedule is given by $r(b)=\sigma \cdot \exp \left\{-\int \psi(b) d b\right\}-(1-\lambda) / \lambda$, where $\sigma$ is a constant of integration whose value is derived from the boundary condition $r(\pi)=1$. 


\section{The Open Procedure}

Under the closed procedure, the legislator was unable to respond to the agency's budget request with a counterproposal for the agency's budget; $L$ could only influence the budget following a (successful) audit. As we have seen, this has implied a degree of agenda control on the part of the agency that has resulted in budgets known to be above the true cost of services. In this section we relax this assumption by allowing the legislator to make a counterproposal, which the agency can then either accept or reject; if rejected then no exchange occurs. As discussed in the introduction, I label this the open procedure. In this framework a strategy for the agency will consist of a budget request $\beta_{\mathrm{o}}:[0, v] \rightarrow \mathbf{R}$, as well as a response $\sigma_{\mathrm{o}}$ : $[0, v] \times \mathbf{R} \rightarrow[0,1]$, where $\sigma_{o}(c, p)$ is the probability with which $A$ accepts a counterproposal of $p$ by $L$, given cost of services $c$. Feasibility requires that the agency cannot have a budget less than its cost, so that $\sigma_{\mathrm{o}}$ $(c, p)=0$ if $p<c$, and sequential rationality requires that $A$ accept any budget greater than or equal to cost, $\sigma_{o}(c, p)=1$ if $p \geqslant c .{ }^{12}$ Henceforth, we can suppress the function $\sigma_{o}$, since the equilibrium response to any counterproposal is fixed. For the legislator, a strategy will consist of a decision for each possible request either to accept, reject, audit, or make a counterproposal. Without loss of generality, we can simplify $L$ 's strategy by noting that rejecting a budget request is equivalent to making a counterproposal of $p=0$, while accepting a request of $b$ is akin to making a counterproposal of $p=b$. Thus we can restrict attention to strategies of the form $\left(\alpha_{o}, \rho_{0}\right)$, where $\alpha_{o}: \mathbf{R} \rightarrow[0,1], \rho_{o}: \mathbf{R} \rightarrow \mathbf{R}$, and $\alpha_{o}(b)$ gives the probability with which $L$ makes a counterproposal following a budget request of $b, \rho_{o}(b)$ gives the counterproposal, and $1-\alpha_{o}(b)$ gives the probability of audit following a budget request of $b$.

For the agency, then, the expected utility from requesting a budget of $b$, given the strategy $\left(\alpha_{0}, \rho_{0}\right)$ by the legislator, is $E U_{A}$ $\left(b, c ; \alpha_{0} \cdot \rho_{0}\right) \equiv \alpha_{o}(b) \cdot \rho_{o}(b)+\left[1-\alpha_{o}(b)\right] \cdot c$ if $\rho_{0}(b) \geqslant c$ and is equal to $\left[1-\alpha_{o}(b)\right] \cdot c$, otherwise. As in the basic model the expected utility for the legislator from any strategy will in general depend on $L$ 's beliefs $\mu$ concerning the true cost of services, where now this belief also influences the payoff to $L$ 's counterproposal as well:

$$
\begin{aligned}
E U_{L}\left(b, \alpha_{o} \cdot \rho_{o} ; \mu\right) \equiv & \alpha_{o}(b) \cdot \int_{c}^{\rho_{o}(b)}\left[v-\rho_{o}(b)\right] \mu(c \mid b) d c \\
& +\left[1-\alpha_{o}(b)\right] \cdot\left[v-c_{\mu}-k\right] .
\end{aligned}
$$

${ }^{12}$ In the alternative "variable quality" model in note 6 , the agency would accept budgets less than cost, but produce lower-quality services. This would alter the equilibrium counterproposal by the legislator somewhat, yet not affect the equilibrium budget strategy of the agency. 


\section{Equilibrium Behavior}

Consider the legislator's decision problem. Given beliefs $\mu, L$ can solve for the optimal counterproposal:

$$
\max _{p} \int_{c}^{p}(v-p) \mu(c \mid b) d c
$$

denote this value as $p(\mu)$. Sequential rationality requires that $\rho_{0}(b)$ $=p(\mu(\cdot \mid b))$, where this price is not a function of the audit cost $k$. In addition we can say something about this counterproposal as a function of the support of the belief $\mu$. Let $c_{L}$ and $c_{H}$ be the lowest and highest cost types requesting the budget $b$, respectively; then clearly $p(\mu) \leqslant c_{H}$, since pricing strictly above $c_{H}$, is dominated by pricing at $c_{H}$; similarly $p(\mu)>$ $c_{L}$, since otherwise $L$ receives zero utility from the counterproposal. Comparing the expected utility generated by $p(\mu)$ with $\left(v-c_{\mu}-k\right)$, the utility from auditing, will determine the legislator's optimal decision.

Now consider the agency's decision problem. Since its final budget will be equal either to the true service cost (if audited) or the counterproposal by the legislator (if accepted), the budget request by the agency plays a purely informational role in the process; the only important feature of the request is the information associated with it in terms of which cost types make that request. ${ }^{13}$ It is clear that an equilibrium budget request strategy will never possess a separating region in which $\beta_{\mathrm{o}}$ reveals the true cost of services, as was the case under the closed procedure (when $k<$ $k^{*}$ ). Revealing the true cost $c$ would generate an equilibrium counterproposal equal to $c$, thus providing an incentive for the agency to mimic the budget requests of higher cost types. Another possibility is that $\beta_{o}$ is a step function, so that the budget requests revealed some information. Such "partially revealing" strategies are common in these sorts of models (see Crawford and Sobel, 1982), and indeed that is the behavior exhibited in a model similar to ours in Gilligan and Krehbiel (1987).

Lemma A1 in Appendix A shows formally that (with imperfect auditing) the equilibrium counterproposals associated with all cost types $c \in[0, v]$ must coincide. ${ }^{14}$ Hence, the only equilibria under the open pro-

${ }^{13}$ This is sometimes referred to as "costless" signaling, in that the signal (in this case the requested budget) does not directly enter into the payoffs of the players. Under the closed procedure, the selection of a budget request is "costly" in that it might actually be the final budget of the agency.

${ }^{14}$ Although other equilibria may exist with perfect auditing, the equilibrium outcome is essentially unique when $\lambda<1$, and this equilibrium occurs when $\lambda=1$ as well. In mathematical parlance the equilibrium correspondence is upper hemicontinuous, rather than continuous, at $\lambda=1$. 
cedure will be completely uninformative: all cost types request the same budget. The legislator's decision calculus is then predicated simply on the prior probability $f(\cdot)$. Define $p^{*}$ as the counterproposal which solves

$$
\max _{p} \int_{0}^{p}(v-p) f(c) d c
$$

$p^{*}$ is thus the equilibrium counterproposal. Clearly $p^{*} \in(0, v)$, since at either $p=0$ or $p=v$ the expected utility for the legislator is zero. Thus $p^{*}$ will satisfy the first-order condition

$$
(v-p) f(p)-\int_{0}^{p} f(c) d c=0,
$$

as well as the second-order condition

$$
(v-p) f^{\prime}(p)-2 f(p)<0 .
$$

Define $k^{* *}$ as the value of the audit cost $k$ which solves

$$
\int_{0}^{v}(v-c) f(c) d c-k-\int_{0}^{p^{*}}\left(v-p^{*}\right) f(c) d c=0
$$

Thus, if $k<k^{* *}$ and all cost types make the same budget request, the legislator will prefer to audit; if $k>k^{* *} L$ will prefer to make a counterproposal equal to $p^{*}$.

Proposition 5: If $k<k^{* *}$, then the following constitute sequential equilibrium strategies:

$$
\begin{array}{cc}
\beta_{o}^{*}(c)=v & \text { for all } c \in[0, v], \\
\alpha_{o}^{*}(b)=0 & \text { for all } b \in[0, v] .
\end{array}
$$

Defining the functions $B_{0}(c ; k, v), V_{0}(k, v), P_{0}(k, v)$, and $N_{0}(k, v)$ as under the closed procedure, we have that for $k<k^{* *}$,

$$
\begin{aligned}
& B_{0}(c ; k, v)=c, \quad \text { for all } c \in[0, v], \\
& V_{\mathrm{o}}(k, v)=\int_{0}^{v}(v-c) f(c) d c-k, \\
& P_{\mathrm{o}}(k, v)=1,
\end{aligned}
$$

and

$$
N_{\mathrm{o}}(k, v)=0 .
$$

Proposition 6: If $k>k^{* *}$, the following constitute sequential equilibrium strategies: 


$$
\begin{aligned}
& \beta_{o}^{*}(c)=v \text { for all } c \in[0, v], \\
& \alpha_{o}^{*}(b)=1 \text { for all } b \in[0, v], \\
& \rho_{o}^{*}(b)= \begin{cases}0 & \text { if } b<v \\
p^{*} & \text { if } b=v\end{cases}
\end{aligned}
$$

For $k>k^{* *}$, then,

$$
\begin{aligned}
& B_{0}(c ; k, v)= \begin{cases}p^{*} & \text { if } c \leqslant p^{*} \\
0 & \text { if } c>p^{*}\end{cases} \\
& V_{\mathrm{o}}(k, v)=\int_{0}^{p^{*}}\left(v-p^{*}\right) f(c) d c, \\
& P_{\mathrm{o}}(k, v)=0,
\end{aligned}
$$

and

$$
N_{\mathrm{o}}(k, v)=\int_{p^{*}}^{v} f(c) d c .
$$

As an example, suppose that $f(\cdot)$ is uniform; then $k^{* *}$ is $v / 4$, and the optimal counterproposal $p^{*}$ is $v / 2$.

Although other equilibria exist, since the choice of (pooled) budget request is somewhat arbitrary as is to some extent the out-of-equilibrium responses by $L$, the key is that in any equilibrium no new information will be transmitted from the agency to the legislator. Thus, in addition to playing no substantive role in determining the budget, in equilibrium the budget request strategy of the agency plays no informational role as well. In particular, the parameters $k$ and $v$ will not affect the equilibrium budget strategy of the agency. For $k<k^{* *}$, these parameters do not affect the legislator's strategy either, while for $k>k^{* *} L$ 's equilibrium counterproposal will be a function of $v$, but not $k$. In Appendix A it is shown that $\partial p^{*} / \partial v>0$, so that an increase in the legislator's value of services will lead to an increase in the equilibrium counterproposal. Hence, the equilibrium budget of the agency $B_{\mathrm{o}}$ increases with $v$ for $c \leqslant p^{*}$, as does the legislator's expected utility $V_{\mathrm{o}}$. Whether or not $N_{\mathrm{o}}$ increases or decreases with $v$ will in general depend on the prior probability $f(\cdot)$.

Notice that if $k<k^{* *}$ the equilibrium outcome is inefficient due to the legislative auditing; yet an exchange always occurs. If $k>k^{* *}$, on the other hand, the legislator never audits, yet if $c>p^{*}$ an exchange does not occur, even though an exchange at a price $p \in[c, v)$ would be beneficial to both parties. The reason they cannot agree to such an exchange, of course, is due in part to the informational asymmetry. Yet as the closed procedure shows this is not the sole source of the difficulty, since under that procedure an exchange would always take place. The problem in the open procedure is pre- 
cisely the inability of the legislator to commit to any counterproposals and auditing schedules that are not sequentially rational. In equilibrium the legislator must make the auditing decisions and counterproposals optimally according to the information concerning service cost, and in this procedure the transmission of any information on the part of the agency will not constitute equilibrium behavior.

As discussed above, the budget request strategies in Propositions 5 and 6 are equilibrium strategies with imperfect auditing as well. The only difference in the legislator's strategy will be in the determination of the critical value $k^{* *}$. Following an unsuccessful audit, $L$ will select a counterproposal equal to $p^{*}$, so that this critical value will be a function of $\lambda$ (the probability of a successful audit) as well as the payoff associated with $p^{*}$. Similarly, the agency's attitudes toward risk play no role in the determination of the equilibrium behavior.

\section{A Comparison of Procedures}

We compare the open and closed budgetary procedures (with perfect auditing) via the payoffs to the agency and legislator associated with the equilibrium behavior described in Propositions 1, 2, 5, and 6. We say that the closed procedure Pareto-dominates the open procedure if $B(c ; k, v) \geqslant B_{0}(c ; k, v)$ for all $c \in[0, v]$ and $V(k, v) \geqslant V_{o}(k, v)$, with strict inequality for either $L$ or for some cost type $c ; 15$ similarly define Pareto-domination by the open procedure. An obvious prediction ex ante is that $B(c ; k, v)>B_{0}(c ; k, v)$ and $V_{0}(k, v)>V(k, v)$, so that the agency strictly prefers the closed procedure to the open while the legislator strictly prefers the open to the closed. As we shall see, this is not always the case.

In both procedures there exists a critical value of the audit cost where the equilibrium strategies change from one "form" to another. From equations (1) and (19), it is clear that $k^{*}$, the critical value under the closed procedure, is greater than $k^{* *}$, its counterpart under the open procedure. Thus we shall compare the equilibria for three different regions of the audit cost: $k<k^{* *}, k \in\left(k^{* *}, k^{*}\right)$, and $k>k^{*}$.

(1) $k<k^{* *} . B(c ; k, v)>c$, and $B_{0}(c ; k, v)=c$, forall $c \in[0, v)$; that is, under the closed procedure the expected budget for the agency is greater than the service $\operatorname{cost} c$, while under the open procedure the expected budget is exactly equal to the service cost. Thus, as predicted, the agency strictly prefers the closed procedure to the open procedure for all realizations of the service cost. Recall from equation (5) that the expected utility for the legislator under the closed procedure is $\int_{0}^{c^{\prime}}(v-c-k) f(c) d c$. From the definition of

${ }^{15}$ In the incomplete information literature, this is known as "interim" domination, as opposed to ex ante or ex post domination. Holmstrom and Myerson (1983) argue that this is the appropriate concept for situations such as the one studied here. 
$c^{\prime}$ in equation (2), however, this is equal to $\int_{0}^{v}(v-c-k) f(c) d c$, which is exactly equal to the legislator's expected utility under the open procedure, equation (21). Hence, the legislator is actually indifferent between the procedures if the audit cost $k$ is less than $k^{* *}$. Although this seems paradoxical, recall that even though in the closed procedure the legislator does not have the option to respond to a request with a counterproposal, $L$ is not completely at the whim of the agency. The ability to audit, and subsequently to impose a budget equal to the service cost, mitigates the ability of the agency to extract all of the gains from the exchange. Furthermore, in equilibrium the legislator must adopt an interior auditing strategy so as to provide the incentive for the agency to reveal information concerning the service cost, implying that the budget strategy must be sensitive to the payoff to the legislator.

Since the agency strictly prefers the closed procedure, we have the following result.

Proposition 7: If $k<k^{* *}$, the closed procedure Pareto-dominates the open procedure.

With $\lambda$ less than (but close to) 1 , this result will continue to hold, where now the legislator will strictly prefer the closed procedure.

(2) $k \in\left(k^{* *}, k^{*}\right)$. Under the closed procedure, the agency's expected budget is still greater than its service cost, while under the open procedure the budget is either $p^{*}$ or else no exchange takes place. In this instance it is clear that for some service costs (i.e., the lowest) the expected budget may actually be greater under the open procedure. For example, let $f(\cdot)$ be uniform, $v=1$, and $k \in(1 / 4,1 / 2)$. Then for $c=0, B(0 ; k, v)=$ $k$, while $B_{0}(0 ; k, v)=p^{*}=1 / 2$. Thus, depending on the parameters of the model and the service cost, the agency might actually prefer the open procedure to the closed procedure. In general, however, this preference is ambiguous.

For the legislator it is clear that the open procedure is strictly preferred to the closed procedure. To see this, note that from above if under the open procedure the legislator audits, $L$ receives exactly the same utility as under the closed procedure; yet since $k>k^{* *}, L$ prefers to offer a counterproposal rather than audit. Thus the utility for $L$ under the open procedure is greater than that under the closed.

(3) $k>k^{*}$. Under the closed procedure, the agency's expected budget is $B(c ; k, v)=v$, so that regardless of the service cost the agency extracts all of the available surplus from the exchange. Since $B_{o}(c ; k, v)=$ $p^{*}<v$ or there is no exchange, the agency prefers the closed procedure. Likewise, the legislator prefers the open procedure. Hence, in this case nei- 
ther procedure Pareto-dominates the other. What is of interest is to note that the trade-off between procedures can be thought of as one between equity versus efficiency. Recall that the equilibrium outcome under the closed rule is efficient; exchange always occurs and auditing never occurs. Yet the payoffs are highly skewed; the agency receives all of the surplus. On the other hand, the equilibrium outcome under the open rule is inefficient; sometimes no exchange occurs, even though one would be beneficial. Yet the payoffs are more equitable, in that (in an ex ante sense) both the agency and legislator receive some of the gains from exchange. From this it is clear that, for relatively high audit cost (i.e., $k>k^{*}$ ), the social cost of achieving an equitable solution in the presence of the informational asymmetry analyzed here lies in the inability to realize all of the gains from exchange.

\section{Conclusion}

This paper has developed and analyzed a simple model of the interaction between a legislature and an agency in the determination of the agency's budget when only the agency is aware of the cost of its services. The legislature has the ability to verify the agency's information, but only at a cost. Further, the legislature is unable to commit to an auditing schedule ex ante, but rather must make its auditing decisions in a sequentially rational fashion. The presence of this auditing cost implies that it may be optimal for the legislature to forgo an audit if the costs outweigh the benefits. Under the closed procedure, in which the legislature is not able to offer a counterproposal to the agency, it was shown that, if the audit cost is not too high, the legislature's optimal auditing schedule is such that the agency has an incentive to request lower budgets if the true cost of services is low, thereby signaling this cost through its budget request. Further, the agency is unable to extract all of the gains from trade by its agenda control. Under the open procedure, on the other hand, the agency reveals nothing about its service cost, and the legislature proceeds, based on its prior information, with either an audit or a counterproposal, depending on the audit cost. A principal result is that, for relatively low audit costs, the closed procedure is actually Paretosuperior to the open procedure, in particular generating a more efficient outcome. This can be compared with the work of Gilligan and Krehbiel (1987) on open versus closed rules in Congress, where the relevant committee possesses an informational advantage vis-à-vis the floor concerning policy outcomes. Gilligan and Krehbiel show that, in their environment as well, a closed rule may be Pareto-preferred to an open rule due to the incentives for revealing information inherent in each process.

As noted in the introduction, the budgetary process in reality resembles a multiperiod interaction between the agency and legislature, implying that the most fruitful line of future research will be in extending the above analy- 
sis to such a setting. Other relevant extensions would include having the legislature's value of the agency's services be known only to the legislature, thus implying a two-sided informational asymmetry. We conjecture that this would generate more "separation" on the part of the agency, as well as change the nature of the agency's risk attitudes on the equilibrium predictions. Also, by assuming an elastic legislative demand, quantity as well as price decisions become relevant; this would also render the model more comparable to previous analyses which have as their focus the equilibrium quantity of services provided and the associated inefficiency. Another interesting extension would be to assume that the agency has a set of possible services, each with a value to the legislature and a cost known only to the agency. The issue then is which service (or set of services) will be acquired, and at what price. These topics should be addressed in future research.

\section{Manuscript submitted 14 June 1988 \\ Final manuscript received 10 November 1988}

\section{APPENDIX A}

\section{Definition of the Universally Divine Equilibrium Concept}

Most of the extant equilibrium refinements place restrictions on out-of-equilibrium beliefs based in part on the equilibrium payoffs associated with each "type" (e.g., cost of services in this model) and their subsequent willingness and ability to "defect" from the equilibrium to any particular signal. The universal divinity criterion requires that out-of-equilibrium beliefs place positive probability only on those cost types which would be "most likely" to deviate from the equilibrium and request the (previously) out-of-equilibrium budget. For any $b<v$, and given equilibrium strategies $\beta^{*}, \alpha^{*}$ such that $\beta^{*-1}(b)=\phi$, define $\theta\left(c, b ; \beta^{*}, \alpha^{*}\right)$ $\equiv\left\{E U_{A}\left(\beta^{*}(c), c ; \alpha^{*}\right)-c\right\} /(b-c)$ as the probability of acceptance which makes $A$ with cost $c$ indifferent between staying with the equilibrium and requesting $b$; since $b<v$ the probability of audit at $b$ is then $1-\theta$. Thus in equilibrium it must be that $\alpha_{1}^{*}(b) \leqslant \theta$ $(c, b) \forall c$. The cost types which are "most likely" to deviate and request $b$, given $\beta^{*}$ and $\alpha^{*}$, are then those that minimize $\theta(c, b)$.

Definition: A universally divine equilibrium consists of strategies $\beta^{*}, \alpha^{*}$, and beliefs $\mu^{*}$, such that

(1) $\forall c \in[0, v], \beta^{*}(c)$ maximizes $E U_{A}\left(b, c ; \alpha^{*}\right)$;

(2) $\forall b \in \mathbf{R}, \alpha^{*}(b)$ maximizes $E U_{L}\left(b, \alpha ; \mu^{*}\right)$;

(3) if $\beta^{*-1}(b) \neq \phi$, then $\mu^{*}(\cdot \mid b)$ is derived via Bayes's Rule according to $\beta^{*}$ and $f(\cdot)$

(4) if $\beta^{*-1}(b)=\phi$, then $\mu^{*}\left(c^{\prime} \mid b\right)>0$ only if $c^{\prime} \in \underset{c}{\operatorname{argmin}} \theta\left(c, b ; \beta_{2}^{X} \alpha^{*}\right)$.

Proof of Propositions 1 and 2: Let $\beta, \alpha$, be universally divine equilibrium strategies.

(I) $\forall_{c}$ such that $\beta(c)<v, \alpha_{1}(\beta(c))>0$.

Suppose not; define $b^{+}=\sup _{c}\left\{\beta(c)<v: \alpha_{1}(\beta(c))>0\right\}$. Then $b^{+} \in[k, v)$, and $\forall_{c}<b^{+}, \alpha_{1}(\beta(c))>0$. Define $\hat{c}=\min \left\{c: \alpha_{1}(\beta(c))=0\right\}$ and select $b \in(\hat{c}$, min $\{v, \hat{c}+k\}$ ); thus $b>b^{+}$and $\alpha_{1}(b)=0$. If $\beta^{-1}(b) \neq \phi$, then $\beta^{-1}(b) \subset[\hat{c}, b]$, so that given beliefs $\mu(\cdot \mid b), c_{\mu}+k>b$. Thus $v-b>v-c_{\mu}-k$, which implies that in equilibrium it must be that $\alpha_{1}(b)=1$, contradicting the assumption that $b>b^{+}$. If $\beta^{-1}$ $(b)=\phi$, then $\theta(\hat{c}, b)=0$ and $\theta(c, b)=0$ only if $c \in[\hat{c}, b)$, so that again $c_{\mu}+k>b$ and $\alpha_{1}(b)=\alpha_{1}(b)=1$, contradicting the definition of $b^{+}$.

QED

(2) If $\beta^{-1}(v) \neq \phi$, then $\alpha_{1}(v)+\alpha_{2}(v)=1$. 
Clearly $\alpha_{1}(v)=0$ and $\alpha_{2}(v)<1$ implies $\beta^{-1}(v)=\phi$, so suppose that $\alpha_{1}(v)$ $+\alpha_{2}(v)<1$ and $\alpha_{1}(v)>0$. Define $\hat{c} \equiv \alpha_{1}(v) \cdot v /\left(1-\alpha_{2}(v)\right)$. By assumption $\hat{c}<v$. Then $\forall c \in(\hat{c}, v), \beta(c) \neq v$, since for any $b \geqslant c \alpha_{1}(b) \cdot b+\left(1-\alpha_{1}(b)\right)$ $\cdot c \geqslant c>\alpha_{1}(v) \cdot v+\alpha_{2}(v) \cdot c$. Thus $\beta(c)<v \forall c \in(\hat{c}, v)$, so that $\alpha_{1}(\beta(c))>$ 0 by result (1) above, which also implies that $\beta(c)>c$ as well. Select $b$ arbitrarily close to $v$ such that $\beta^{-1}(b) \neq \phi$, and define $\Delta(c, b, v) \equiv \alpha_{1}(b) \cdot b+c\left[1-\alpha_{1}(b)-\right.$ $\left.\alpha_{2}(v)\right]-\alpha_{1}(v) \cdot v$ as the difference in the payoffs from proposing $b$ and $v$. Then $\beta(c)=v$ only if $\Delta(c, b, v) \leqslant 0$ and $\beta(c)=b$ only if $\Delta(c, b, v) \geqslant 0$. Thus if $\beta(c)=v$, then there does not exist $c^{\prime}<c$ such that $\beta\left(c^{\prime}\right)=b$, so that

$$
\max \{c: \beta(c)=v\}<\min \{c: \beta(c)=b\} .
$$

Thus $c_{\mu(v)}<c_{\mu(b)}$, and since $\alpha_{1}(v)>0$ and $v>b$, it must be that $\alpha_{1}(b)=1$. But since $b$ is chosen arbitrarily close to $v, \alpha_{1}(b)=1$ and $\alpha_{1}(v)<1$ imply that it will not be optimal for any $c \in[0, v)$ to propose $v$, which contradicts the assumption that $\beta^{-1}(v) \neq \phi$. QED

Thus in any equilibrium it must be that $\forall c \in[0, v) \alpha_{1}(\beta(c))>0$, and $\alpha_{2}(\beta(c))=$ $1-\alpha_{1}(\beta(c))$, so that all cost types have their (equilibrium) request accepted with positive probability and never have their services rejected.

(3) $\beta$ is monotone increasing on $[0, v)$.

By result (2) we can write the "incentive compatability" condition for an equilibrium as

$$
\alpha_{1} \cdot(b-c) \geqslant \alpha_{1}^{\prime} \cdot\left(b^{\prime}-c\right),
$$

where $\alpha_{1}=\alpha_{1}(\beta(c)), \alpha_{1}^{\prime}=\alpha_{1}\left(\beta\left(c^{\prime}\right)\right), b=\beta(c), b^{\prime}=\beta\left(c^{\prime}\right)$. The above equation says that no cost type has an incentive to "imitate" another cost type in equilibrium. Let $c<$ $c^{\prime}$; applying this condition to types $c$ and $c^{\prime}$ gives

$$
\left(b^{\prime}-c^{\prime}\right) /\left(b-c^{\prime}\right) \geqslant \alpha_{1} / \alpha_{1}^{\prime} \geqslant\left(b^{\prime}-c\right) /(b-c) .
$$

Canceling terms, we get that

$$
c^{\prime} \cdot\left(b^{\prime}-b\right) \geqslant c \cdot\left(b^{\prime}-b\right),
$$

so that since $c^{\prime}>c$ it must be that $b^{\prime} \geqslant b$, proving the claim.

QED

Since $\beta$ is monotone increasing, it will have at most a countable number of jump discontinuities, so that we can talk about "separating" or "pooling" segments, where the jumps occur at the end of the segments. Further, by the continuity of $A$ 's preferences, a cost type at which (according to $\beta$ ) there is a jump must be indifferent between the two possible budget requests. Now if a segment $C \subset[0, v)$ is separating, it must be that $\beta(c)=c+$ $k, \forall c \in C$, so that $L$ will be indifferent and hence able to ramdomize. But this, along with the above results, implies that costs $c \in(v-k, v)$ must be pooling at the budget request $v$. If $\alpha_{1}(v)=1$, then all cost types would request $v$, which will only be an equilibrium if $k>k^{*}$, thus proving Proposition 2. If $k<k^{*}$ and $\alpha_{1}(v) \in(0,1)$, then it must be that $L$ is indifferent between accepting and auditing a request of $v$. But since $\beta$ is monotone increasing, this implies that $\beta(c)=v \forall c \in\left(c^{\prime}, v\right)$, where $c^{\prime}$ is defined in equation (2). Thus there will be a jump discontinuity in $\beta$ at $c=c^{\prime}$.

The remainder of the proof follows from the application of the Banks-Sobel criterion on out-of-equilibrium beliefs to the set of sequential equilibria where $c<c^{\prime}$; that is, where there is "enough room" for these types to separate (see, e.g., Reinganum and Wilde, 1986). The particular audit strategy in Proposition 1 gives cost types $c<c^{\prime}$ the incentive to request $\beta(c)=c+k$. To see this, note that since $r(b)$ is differentiable on $\left[k, c^{\prime}+k\right]$ the optimal budget request for $c \in\left[0, c^{\prime}\right)$ on the set of requests $\left[k, c^{\prime}+k\right]$ is characterized by the firstorder condition 


$$
\frac{\partial r}{\partial b}(b-c)+r(b)=0 .
$$

Since $r(b)=\exp \{(k-b) / k\}$, this reduces to

$$
\begin{aligned}
& \exp \{(k-b) / k\} \cdot(c-b) / k+\exp \{(k-b) / k\}= \\
& \exp \{(k-b) / k\} \cdot[(c-b) / k+1]=0 .
\end{aligned}
$$

Since $\exp \{(k-b) / k\}>0 \forall b<\infty$ this equation is solved when $(b-c) / k=1$, implying that the optimal budget request is $b=c+k$. Further, since $\alpha_{1}(v)$ is set such that $c=c^{\prime}$ is indifferent between pooling at $v$ and separating at $c^{\prime}(k)=k$, no $\cos t c<c^{\prime}$ will have an incentive to request $b=v$ as well. Finally, for all $b \in\left(c^{\prime}+k, v\right), c^{\prime}=$ $\min _{c} \theta(c, b)$, so that $L$ places probability 1 on any such out-of-equilibrium requests coming from $c=c^{\prime}$. This then implies that for all such requests $\alpha_{1}(b)=0$.

This then concludes the proof.

QED

Corollary AI: $\partial c^{\prime} / \partial k<0$.

Proof: From equation (2) we have that

$$
\frac{\partial c^{\prime}}{\partial k}=-\frac{\partial G / \partial k}{\partial G / \partial c^{\prime}}
$$

Since $\partial G / \partial k=1$ and

$$
\frac{\partial G}{\partial c^{\prime}}=\int_{c^{\prime}}^{v}\left(c-c^{\prime}\right) f(c) d c /\left[\int_{c}^{v} f(c) d c\right]^{2}>0,
$$

it follows by equation (A7) that $\partial c^{\prime} / \partial k<0$.

QED

Corollary A2: If $k<k^{*}$, then

(1) $\forall c \in[0, v] \partial B / \partial k>0$;

(2) $\forall c \in\left[0, c^{\prime}\right) \partial B / \partial v=0$;

(3) $\forall c \in\left[c^{\prime}, v\right]$, if $\partial c^{\prime} / \partial v>0$ then $\partial B / \partial v \lessgtr 0$ as $c \lessgtr c^{+}$, where $c^{+}$solves

$k \cdot\left(c-c^{\prime}\right) /(v-c)-\frac{\partial c^{\prime}}{\partial v}\left(v-c^{\prime}-k\right)=0$.

Proof: (1) From equation (3) we have that, for $c<c^{\prime}$,

$$
\frac{\partial B}{\partial k}=\exp \{-c / k\} \cdot(1+c / k)>0 .
$$

For $c>c^{\prime}$ equation (4) implies

$$
\frac{\partial B}{\partial k}=\exp \left\{-c^{\prime} / k\right\}(v-c) /\left(v-c^{\prime}\right)\left[1+c^{\prime}+\frac{\partial c^{\prime}}{\partial k} \cdot\left(k-v+c^{\prime}\right) /\left(v-c^{\prime}\right)\right] .
$$

Since $v-c^{\prime}>k$ and $\partial c^{\prime} / \partial k<0$, the term in brackets in equation (A11) is positive, so that $\partial B / \partial k>0$.

(2) From equation (3) it follows that $\partial B / \partial v=0$ for costs $c<c^{\prime}$.

(3) For costs $c>c^{\prime}$ the sign of $\partial B / \partial v$ will depend on the sign as well as possibly the magnitude of $\partial c^{\prime} / \partial v$ :

$$
\frac{\partial B}{\partial v}=\exp \left\{-c^{\prime} / k\right\} \cdot\left\{\left[\frac{\partial c^{\prime}}{\partial v}\left(k+c^{\prime}-v\right)-k\right] \cdot(v-c)+k \cdot\left(v-c^{\prime}\right) /\left(v-c^{\prime}\right)^{2} .\right.
$$


Rearranging terms, we get that

$$
\operatorname{sgn}\{\partial B / \partial v\}=\operatorname{sgn}\left\{\frac{\partial c^{\prime}}{\partial v}\left(k+c^{\prime}-v\right)(v-c)+k\left(c-c^{\prime}\right)\right\} .
$$

Since $v>c^{\prime}+k$ and $c>c^{\prime}$, if $\partial \mathrm{c}^{\prime} / \partial v<0$ then $\partial B / \partial v>0$. Thus if more cost types pool at $b=v$ when the value $v$ increases, the expected budget for those that pool at $b=v$ increases. Suppose instead that $\partial c^{\prime} / \partial v>0$; then

$$
\frac{\partial B}{\partial v} \mid\left(c^{\prime}\right)<0, \quad \text { and } \frac{\partial B(v)}{\partial v}>0,
$$

so that the direction of change in the expected budget will depend on the cost $c$. The cost $c^{+}$ is then defined as the value such that $\partial B / \partial v=0$, derived from equation (A12). QED

Corollary A3: If $k<k^{*}$ then

(1) $\partial V / \partial k<0$

(2) if $\partial c^{\prime} / \partial v>0$ then $\partial V / \partial v>0$.

Proof: (1) From equation (5)

$$
\frac{\partial V}{\partial k}=\frac{\partial c^{\prime}}{\partial k}\left(v-c^{\prime}-k\right) f\left(c^{\prime}\right)-\int_{0}^{c^{\prime}} f(c) d c
$$

so that since $\partial c^{\prime} / \partial k<0$ we have that $\partial V / \partial k<0$.

(2) From equation (5)

$$
\frac{\partial V}{\partial v}=\frac{\partial c^{\prime}}{\partial v}\left(v-c^{\prime}-k\right) f\left(c^{\prime}\right)+\int_{0}^{c^{\prime}} f(c) d c
$$

so that if $\partial c^{\prime} / \partial v>0$ then $\partial \mathrm{V} / \partial \mathrm{v}>0$.

QED

Corollary A4: If $k<k^{*}$ and equation (8) holds, then

(1) $\partial P / \partial k<0$;

(2) if $\partial c^{\prime} / \partial v>0$ then $\partial \mathrm{P} / \partial \mathrm{v}>0$.

Proof: (1) From equation (6)

$$
\begin{aligned}
\frac{\partial P}{\partial k}= & \exp \left\{-c^{\prime} / k\right\}[1-k /(v-c)] \cdot\left[\int_{c^{\prime}}^{v} f(c) d c /\left(v-c^{\prime}\right)\right. \\
& \left.-f\left(c^{\prime}\right)\right] \frac{\partial c^{\prime}}{\partial k}-\int_{0}^{c^{\prime}} \exp \{-c / k\}\left(c / k^{2}\right) f(c) d c-\exp \left\{-c^{\prime} / k\right\}\left[c^{\prime} / k\right. \\
& +1] \int_{c}^{v} f(c) d c /\left(v-c^{\prime}\right) .
\end{aligned}
$$

The last two terms are negative and $\partial c^{\prime} / \partial k<0$, so that if equation (8) holds the result follows.

(2) From equation (6)

$$
\begin{aligned}
\frac{\partial P}{\partial v}= & \exp \left\{-c^{\prime} / k\right\}\left[1-k /\left(v-c^{\prime}\right)\right] \cdot\left[\int_{c}^{v} f(c) d c /\left(v-c^{\prime}\right)-f\left(c^{\prime}\right)\right] \frac{\partial c^{\prime}}{\partial v} \\
& +f(v)\left[1-\exp \left\{-c^{\prime} / k\right\} k /\left(v-c^{\prime}\right)\right] \\
& +\left[\exp \left\{-c^{\prime} / k\right\} /\left(v-c^{\prime}\right)^{2}\right] \int_{c^{v}}^{v} f(c) d c .
\end{aligned}
$$

The last two terms are positive, so that if equation (8) holds and $\partial c^{\prime} / \partial v>0$ then $\partial P / \partial v>0$.

QED

Lemma A1: For all equilibria $\beta_{o}, \alpha_{o}, \rho_{0}$ under the open procedure with imperfect auditing, $\rho_{0}\left(\beta_{0}(c)\right)=\rho_{0}\left(\beta_{o}\left(c^{\prime}\right)\right) \forall c, c^{\prime} \in[0, v]$.

Proof: Let $\beta_{0}, \alpha_{0}, \rho_{o}$ be equilibrium strategies.

This content downloaded from 131.215.70.231 on Fri, 18 Mar 2016 16:06:42 UTC All use subject to JSTOR Terms and Conditions 
(1) $\rho_{\mathrm{o}}\left(\beta_{\mathrm{o}}(c)\right)$ is monotone increasing in $c$.

Let $c<c^{\prime}$, and define $p=\rho_{o}\left(\beta_{o}(c)\right), p^{\prime} \doteq \rho_{o}\left(\beta_{o}\left(c^{\prime}\right)\right), r=\alpha_{o}\left(\beta_{o}(c)\right)+(1-\lambda)$ $\left[1-\alpha_{o}\left(\beta_{o}(c)\right)\right], r^{\prime}=\alpha_{o}\left(\beta_{o}\left(c^{\prime}\right)\right)+(1-\lambda)\left[1-\alpha_{o}\left(\beta_{o}\left(c^{\prime}\right)\right)\right]$. Incentive compatability requires that

$$
\begin{aligned}
& r \cdot(p-c) \geqslant r^{\prime} \cdot\left(p^{\prime}-c\right) \\
& r^{\prime} \cdot\left(p^{\prime}-c^{\prime}\right) \geqslant r \cdot\left(p-c^{\prime}\right) .
\end{aligned}
$$

Since $r, r^{\prime}>0$, dividing through by $r / r^{\prime}$ implies that $p \leqslant p^{\prime}$.

Thus $\rho_{0}\left(\beta_{0}\right)$ will be piecewise continuous. As argued in the text, there will not exist any "separating regions in $\beta_{0}$, so that $\rho_{o}\left(\beta_{0}\right)$ will not be strictly increasing on any region. Thus $\rho_{o}\left(\beta_{0}\right)$ will constitute a step function, where for all $c, c^{\prime}$ such that $p \neq p^{\prime}$ (using the above shorthand) there will exist $\epsilon>0$ such that $p-p^{\prime} \mid \geqslant \epsilon$.

Recall that $p(\mu)$ is the optimal counterproposal by $L$ given belief $\mu$; let $\operatorname{supp}(\mu)$ denote the support of the distribution $\mu$.

(2) $\forall \delta>0 \exists c \in \operatorname{supp}(\mu)$ such that $p(\mu)-c<\delta$.

If not, then by lowering the counterproposal by an amount less than $\delta, L$ retains the same cost types accepting the counterproposal while strictly increasing the payoff from the counterproposal.

QED

Now suppose that $\exists c, c^{\prime}$ such that $p \neq p^{\prime}$, and let $p<p^{\prime}$. By (1) $p^{\prime}-$ $p \geqslant \epsilon$ for some $\epsilon>0$, and by (2) $\exists \hat{c} \in \operatorname{supp}(\mu(p))$ such that $p-\hat{c}<$ $\delta \forall \delta>0$. Thus the payoff to $\hat{c}$ from requesting $\beta_{o}\left(c^{\prime}\right)$ is $r \cdot(p-\hat{c})$, while that from requesting $\beta_{0}\left(c^{\prime}\right)$ is $r^{\prime} \cdot(p-\hat{c})$. Since $r, r^{\prime} \in(0,1]$ and $\epsilon>0$, the former is arbitrarily close to zero, while the latter is bounded away from zero by the amount $r^{\prime} \cdot \epsilon$. Thus the original budget request strategy is not an equilibrium.

QED

COROLlaRY A5: $\partial p^{*} / \partial v>0$.

Proof: Implicit differentiation of equation (17) implies that

$$
\frac{\partial p^{*}}{\partial v}=f(p) /\left[2 f(p)-(v-p) f^{\prime}(p)\right],
$$

which by the second-order condition, equation (18), is positive.

QED

\section{REFERENCES}

Banks, Jeffrey, and Joel Sobel. 1987. Equilibrium selection in signaling games. Econometrica, 55:647-61.

Bendor, Jonathan, Serge Taylor, and Roland Van Gaalen. 1987. Politicians, bureaucrats, and asymmetric information. American Journal of Political Science, 31:796-828.

Cho, In-koo, and David Kreps. 1987. Signaling games and stable equilibria. Quarterly Journal of Economics, 102:179-221.

Crawford, Vincent, and Joel Sobel. 1982. Strategic information transmission. Econometrica, 50:1431-51.

Fiorina, Morris, and Roger Noll. 1978. Voters, bureaucrats, and legislators: A rational choice perspective on the growth of bureaucracy. Journal of Public Economics, 9:239-53.

Gilligan, Thomas, and Keith Krehbiel. 1987. Collective decision-making and standing committees: An informational rationale for restrictive amendment procedures. Journal of Law, Economics, and Organization, 3:287-335.

Grossman, Sanford, and Moty Perry. 1986. Perfect sequential equilibria. Journal of Economic Theory, 39:97-119. 
Harsanyi, John. 1967-68. Games with incomplete information played by Bayesian players. Management Science, 14:159-82, 320-34, 486-502.

Holmstrom, Bengt, and Roger Myerson. 1983. Efficient and durable decision rules with incomplete information. Econometrica, 51:1799-1819.

Kreps, David, and Robert Wilson. 1982. Sequential equilibria. Econometrica, 50:863-94.

Kydland, Finn, and Edward Prescott. 1977. Rules rather than discretion: The inconsistency of optimal plans. Journal of Political Economy, 85:473-92.

McCubbins, Mathew, and Thomas Schwartz. 1984. Congressional oversight overlooked: Police patrols vs. fire alarms. American Journal of Political Science, 28:165-79.

Miller, Gary. 1977. Bureaucratic compliance as a game on the unit square. Pubic Choice, 29:37-52.

Miller, Gary, and Terry Moe. 1983. Bureaucrats, legislators, and the size of government. American Political Science Review, 77:297-322.

Niskanen, William. 1971. Bureaucracy and Representative Government. Chicago: AldineAtherton.

Peltzman, Samuel. 1976. Toward a more general theory of regulation. Journal of Law and Economics, 68:211-40.

Reinganum, Jennifer, and Louis Wilde. 1986. Settlement, litigation, and the allocation of court costs. Rand Journal of Economics, 17:557-66.

Spencer, B. 1980. Outside information and the degree of monopoly power of a public bureau. Southern Economic Journal, 47:229-33.

Stigler, George. 1971. The theory of economic regulation. Bell Journal of Economics, 2:3-21.

Weingast, Barry, and Mark Moran. 1983. Bureaucratic discretion or congressional control? Regulatory policymaking by the Federal Trade Commission. Journal of Political Economy, 91:765-800.

Wildavsky, Aaron. 1978. The politics of the budgetary process. Boston: Little, Brown. 